\title{
In-Plane Strengthening Effect of Prefabricated Concrete Walls on Masonry Structures: Shaking Table Test
}

\author{
Weiwei Li, Weiqing Liu, Shuguang Wang, and Dongsheng Du \\ College of Civil Engineering, Nanjing Tech University, Nanjing 211816, China \\ Correspondence should be addressed to Weiqing Liu; wqliu@njtech.edu.cn
}

Received 18 May 2017; Accepted 25 July 2017; Published 24 August 2017

Academic Editor: Vadim V. Silberschmidt

Copyright (C) 2017 Weiwei Li et al. This is an open access article distributed under the Creative Commons Attribution License, which permits unrestricted use, distribution, and reproduction in any medium, provided the original work is properly cited.

\begin{abstract}
The improvement effect of a new strengthening strategy on dynamic action of masonry structure, by installing prefabricated concrete walls on the outer facades, is validated by shaking table test presented in this paper. We carried out dynamic tests of two geometrically identical five-story reduced scaled models, including an unstrengthened and a strengthened masonry model. The experimental analysis encompasses seismic performances such as cracking patterns, failure mechanisms, amplification factors of acceleration, and displacements. The results show that the strengthened masonry structure shows much more excellent seismic capacity when compared with the unstrengthened one.
\end{abstract}

\section{Introduction}

Masonry buildings built by clay bricks and mortar were the most representative constructive system a few decades ago [1]. Most of them were unreinforced, subjected to the results of poor economic condition and poor construction technology in the twentieth century. Recently high seismic vulnerability of this type of construction had been revealed based on the severe damage of buildings after several earthquakes [2, 3], mainly due to the low tensile strength and poor ability of dissipating energy for masonry structures [4]. However, there were a large number of masonry buildings built at seismicity regions in the last century. Recently, the aged material and the declined seismic performance of the built masonry buildings became serious problems for structure safety under earthquake. Unfortunately, it is difficult to reconstruct the old masonry structures due to the high cost. Consequently, the strengthening technology seemed to have several advantages to retrofit the old buildings, such as low cost and excellent improvement of seismic performance $[5,6]$.

A lot of researches showed that experimental method, especially shaking table test, had effectively assisted in the seismic performance study of buildings [7-9]. It is usually considered that the results of shaking table tests provide the most realistic dynamic behaviour of buildings [10]. Recent research efforts have been made to reveal that shaking table tests are also suitable for seismic performance analysis of masonry structures [11-13]. To be considered theoretically, using full-scale experimental models usually provides more accurate mechanical performance of the overall system in shaking table tests. Tu et al. [14] conducted shaking table tests on four full-scale single-story structures to investigate the out-of-plane behaviour of unreinforced masonry panels in $\mathrm{RC}$ frames. Hanazato et al. [15] presented shaking table tests using full-scale model of the timber framed brick masonry walls. Furthermore, based on adequate scaling laws, scaled models are more widely used in the shaking table test. Beyer et al. [16] reported the results of a series of shake-table tests on a half-scale, four-story building with reinforced concrete and unreinforced masonry walls. Ersubasi and Korkmaz [6] conducted experiments on 1/10 scaled and 1-story masonry buildings. Also it is usually considered that shaking table testing is not only used to investigate dynamic behaviour of full masonry structures, but also used to validate new strengthening technology applied on masonry structures. Giamundo et al. [17] showed the experimental results of an innovative reinforcement technique based on inorganic matrixes. Lourenço et al. [18] developed a new construction system for masonry buildings using concrete blocks units and trussed reinforcement and then validated its seismic 
behaviour through shaking table tests. Ma et al. [19] introduced a strengthening strategy to increase the in-plane shear strength and the out-of-plane bending resistance of masonry walls. Oliveira et al. [20] described the experimental behaviour of solid clay brick masonry arches strengthened by glass fiber-reinforced polymer composites. Ismail and Ingham [21] investigated the structural performance of unreinforced masonry walls strengthened by two different types of polymer textile reinforced mortar. Kabashi et al. [5] introduced the fiber-reinforced polymers as a means of increasing the capacity of masonry through strengthening and confinement. Sathiparan et al. [22] reported the seismic behaviour of the polypropylene band mesh retrofitted adobe masonry house. Tomaževič et al. [23] developed a new technology to improve the seismic resistance of old masonry buildings, by means of seismic isolation and confining the structure with CFRP laminate strips. Preciado et al. [24] proposed an approach for the seismic vulnerability reduction of masonry towers, using external prestress. These studies provided useful information that the shaking table testing played an effective role in the research of seismic action for the masonry system.

The present paper reported the seismic performance of two masonry buildings, including a masonry structure built by unreinforced clay brick and mortar and a similar masonry structure strengthened by prefabricated concrete walls. The shaking table tests provide the validation of the strengthening technology applied on masonry structure.

\section{Proposed Systems}

The adopted prototype structure was a five-story house, which usually existed in residential row buildings with an interstory height of $3.0 \mathrm{~m}$. The two outer facades located at the south and the north of the structure had openings percentage of $25.7 \%$ and $26.6 \%$, respectively. The openings percentage was $19.3 \%$ for the interior wall of the structure. The floors and roofs were made of prefabricated reinforced concrete slabs. And the slits between slabs were filled with flexible material. The strengthening strategy presented here was to install prefabricated reinforced concrete walls outside the south wall and north wall of the masonry structure, with a prefabricated reinforced concrete elevator shaft located outside the north strengthened wall. In accordance with the neighbouring house of the row structure, only the outer walls of the building were strengthened. The prototype structure adopted in this paper was located in the middle of the row structure, in the absence of strengthening for the east wall and the west wall. Considering the testing restrictions such as the size and payload of the table, most shaking table tests are carried out on scaled models. In this test, the shaking table was with plan dimensions of $3.36 \mathrm{~m} \times 4.86 \mathrm{~m}$ and a payload of $150 \mathrm{KN}$. Then a reduced 1:4 scale model was decided to be built, by taking into account adequate scaling laws. Usually, the damage patterns and failure mechanisms of the model obtained after seismic loadings are considered similar to those on the prototype building after earthquakes, by applying the similitude between the model and the
TABLE 1: Scale factors adopted in this paper.

\begin{tabular}{lccc}
\hline Parameter & Relationship & Scale factor & Remarks \\
\hline Length $(L)$ & $S_{L}$ & $1: 4$ & $\begin{array}{c}\text { Controlling } \\
\text { factor }\end{array}$ \\
Displacement $(d)$ & $S_{X}=S_{L}$ & $1: 4$ & \\
Stress $(\sigma)$ & $S_{F}=S_{E}$ & $1: 1$ & \\
Strain $(\varepsilon)$ & $S_{\varepsilon}$ & $1: 1$ & \\
Young's Modulus $(E)$ & $S_{E}$ & $1: 1$ & $\begin{array}{c}\text { Controlling } \\
\text { factor }\end{array}$ \\
Mass $(m)$ & $S_{M}=S_{L}{ }^{2} S_{E} / S_{a}$ & $1: 40$ & \\
Time $(t)$ & $S_{T}=S_{L}^{0.5} / S_{a}^{0.5}$ & $1: 3.162$ & \\
Damping & & 1 & \\
Acceleration $(a)$ & $S_{a}$ & $2.5: 1$ & Controlling \\
Weight $(w)$ & $S_{\sigma}=S_{E} S_{L}{ }^{2}$ & $1: 16$ & factor \\
\hline
\end{tabular}

real building and also by adding masses to fill the gap of similitude. The scale factors adopted in this paper were shown in Table 1.

\section{Material Properties}

The masonry unit was built by the clay bricks and mortar, as seen in Figure 1. A standard clay brick had the dimensions of $240 \mathrm{~mm}$ length $\times 120 \mathrm{~mm}$ thickness $\times 54 \mathrm{~mm}$ height. By taking into account the labour intensity and construction accuracy, the clay bricks used in the experimental model were cut from the standard blocks at $1: 2$ scale, with the dimensions of $115 \mathrm{~mm}$ length $\times 60 \mathrm{~mm}$ thickness $\times 27 \mathrm{~mm}$ height. The thickness of the mortar between clay bricks was $5 \mathrm{~mm}$.

According to the scaling laws, the material properties of the experimental model should be equal to the prototype structure. For the built model, the average compressive strength of mortar was $1.45 \mathrm{MPa}$, which was tested from specimens with dimensions of $70 \mathrm{~mm} \times 70 \mathrm{~mm} \times 70 \mathrm{~mm}$. The maximum size of the aggregates adopted in the concrete was half of the size, which was used for prototype structures. The average compression strength of masonry wall units was $2.23 \mathrm{MPa}$, tested from specimens with dimensions of $360 \mathrm{~mm} \times 60 \mathrm{~mm} \times 135 \mathrm{~mm}$, as shown in Figure 1. The cubic compressive strength of concrete was $16 \mathrm{MPa}$. It should be mentioned that the specimens were all cured for 28 days before test. Due to the small reinforcement ratio in prototype structure, we equivalently substituted rebars with galvanized iron wires in slabs and walls. The average yield strength of galvanized iron wire was $451.22 \mathrm{MPa}$ for $12 \#(\phi 3.2)$ wires and was $412.91 \mathrm{MPa}$ for $10 \#(\phi 2.6)$ wires.

\section{Design of the Experimental Models}

Two masonry structural models were proposed in the test. One of the models was a strengthened masonry structure (denoted as SMS model). The other model was built by $1: 2$ scaled clay bricks and mortar and without being strengthened (denoted as USMS model). 


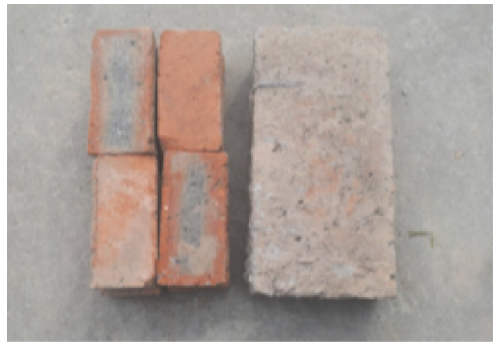

(a) A standard clay brick and the 1:2 scaled clay bricks

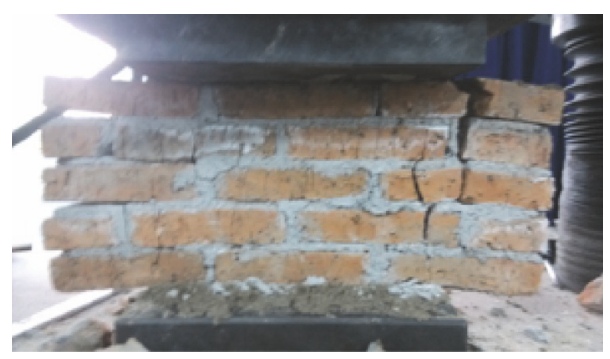

(b) Compressive strength test for masonry wall unit

FIGURE 1: Clay bricks used in the experimental model.

For the USMS model, it was with dimensions of $2.10 \mathrm{~m}$ $\times 2.325 \mathrm{~m}$ in plan and $3.75 \mathrm{~m}$ in height. The interstory height was $0.75 \mathrm{~m}$, and the thickness of masonry walls was $0.06 \mathrm{~m}$. In the north wall, there were several windows openings with sizes of $0.45 \mathrm{~m}$ length $\times 0.45 \mathrm{~m}$ height at each story and with a door opening with sizes of $0.30 \mathrm{~m}$ length $\times 0.675 \mathrm{~m}$ height only at the first story. While in the south wall, there were two windows openings with dimensions of $0.30 \mathrm{~m}$ length $\times$ $0.45 \mathrm{~m}$ height at each story. In the wall located at $B$-axis, as shown in Figure 2, there were two door openings at each story, with sizes of $0.225 \mathrm{~m}$ length $\times 0.675 \mathrm{~m}$ height. Ring beams with section sizes of $60 \mathrm{~mm} \times 45 \mathrm{~mm}$ were located at the second and fourth floors and at the roof. There were also concrete beams located upon the door openings and window openings at each story, with section sizes of $60 \mathrm{~mm}$ $\times 75 \mathrm{~mm}$. Slabs in the floors and roofs were constructed by prefabricated concrete, with 3 varieties of plan dimensions, including $150 \mathrm{~mm} \times 900 \mathrm{~mm}, 150 \mathrm{~mm} \times 600 \mathrm{~mm}$, and $210 \mathrm{~mm}$ $\times 900 \mathrm{~mm}$. And the thickness of slabs was $30 \mathrm{~mm}$. The slabs were longitudinal reinforced by 12\# ( $\phi 3.2)$ galvanized iron wires and transverse reinforced by $10 \#(\phi 2.6)$ galvanized iron wires. The plan view of USMS model was shown in Figure 2.

Additionally, for SMS model, the part of masonry was similar to the USMS model. The prefabricated strengthening wall and the elevator shaft were with thicknesses of $20 \mathrm{~mm}$ and $50 \mathrm{~mm}$, respectively. And they were all reinforced with single-layer and two-way galvanized iron wires by $\phi 2.6 @ 40$. The plan view of SMS model was shown in Figure 2.

The connecting nodes between concrete reinforced wall and masonry wall were shown in Figure 3.

Both of the experimental models were built on reinforced concrete bases, which were used to connect the models to the shaking table through posttensioned steel rods and were 28 days cured before the structures were built. The concrete bases would prevent excessive deformation when transporting the model to the shaking table. The views of constructed models were shown in Figure 4.

\section{Description of the Experimental Program}

The vibration tests of experimental models subject to strong ground motion were carried out on the shaking table. It should be mentioned that models were only seismically loaded at one direction at one time, according to the limitation of one translational degree of freedom for the shaking table.

5.1. Instrumentation. Models were instrumented with four different devices, namely, accelerometers, displacement meters, 3D dynamic displacement acquisition system, and concrete strain gauges. These devices were used to monitor the acceleration, the displacements, and the crack development. There were six accelerometers used in each model, locating at the slab level and arranging from the concrete base to the fifth story. Five displacement meters were used in each model, arranged from the first floor to the roof along the height. The 3D dynamic displacement acquisition system used the camera to measure the displacements of target points, and target points were set on the higher part of each model. The concrete strain gauges were only located at the concrete walls of SMS model, according to the difficulty for measuring local deformation of masonry unites. The strain gauges were arranged in the vertical plane of the concrete wall on the lower part of north side and south side. Both models, including the strengthened one and the unstrengthened one, were similarly instrumented, and the details of instrumentation were presented in Figure 5. In the figure, different devices located on the models at 1-axis walls were denoted as different shape of points. The accelerometers, displacement meters, 3D dynamic target points, and strain gauges were denoted as triangle points, square points, circle points, and rectangle points, respectively.

5.2. Simulation of the Seismic Action. Two natural earthquakes (El Centro wave and Taft wave) and one artificial earthquake (Shanghai wave) were selected to consider as the seismic inputs of the shaking table. The response spectrums of these seismic inputs were matched well with the proposed elastic response spectrum in Shanghai, with design parameters as follows: ground acceleration $0.035 \mathrm{~g}$, ground type II, and 5\% damping. Considering the similitude law, the accelerograms were compressed in time by a factor of 3.162 and the acceleration amplitudes were also multiplied by the factor 2.5 . The proposed elastic response spectrum and the response spectrums obtained from the compressed accelerograms are shown in Figure 6. 


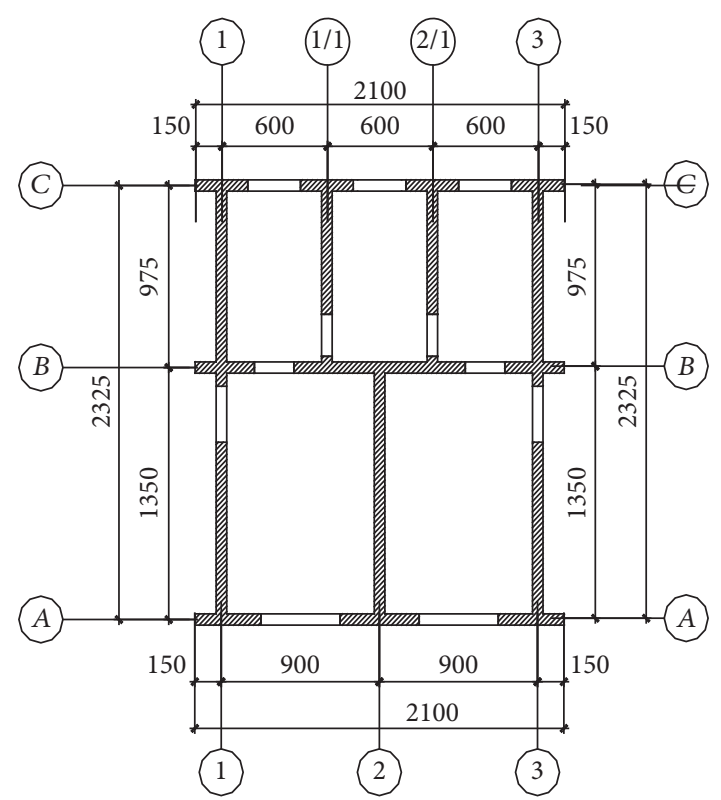

(a) Plan view of USMS model ( $\mathrm{mm}$ )

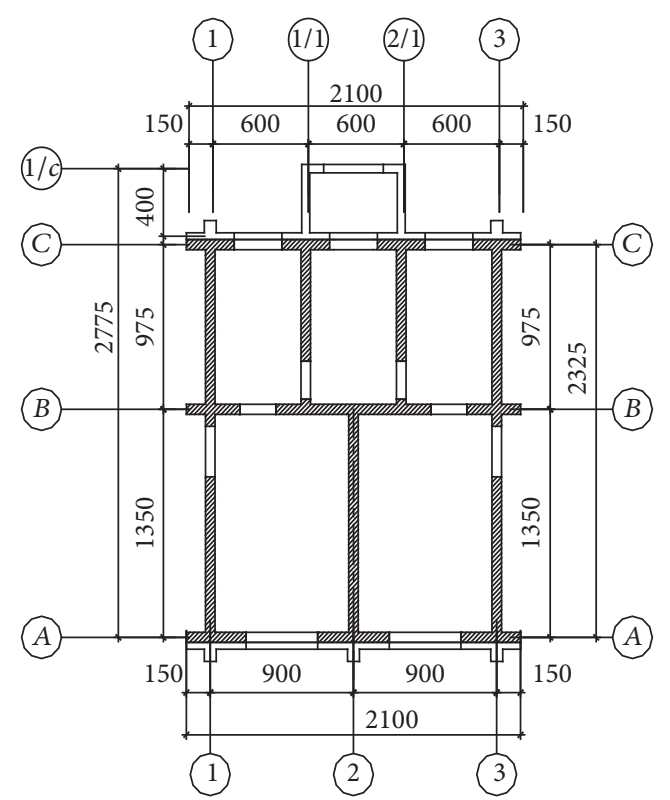

(b) Plan view of SMS model (mm)

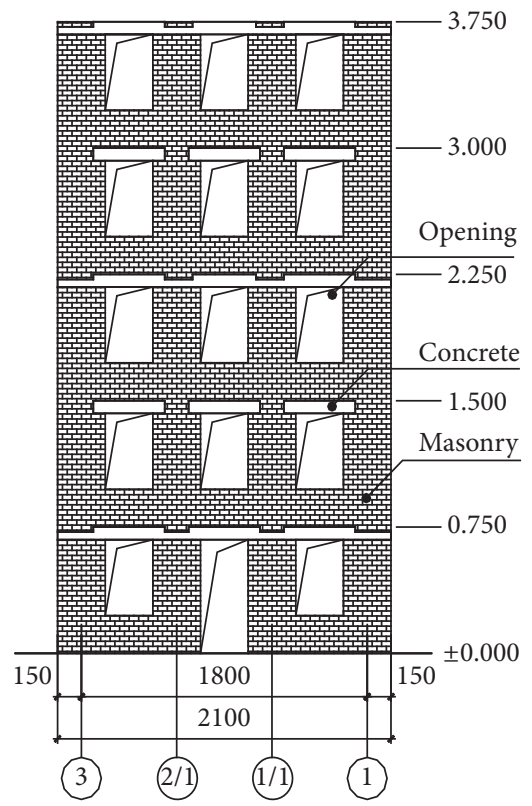

(c) Elevation view of USMS model (m)

FIGURE 2: Plan views and elevation view of experimental models.

The test sequence and the Peak Ground Acceleration (PGA) were summarized in Table 2. Here, it is necessary to explain the naming rules of the terminologies by way of examples. The S7, M7, and L7 refer to PGA level of frequent earthquake, medium earthquake, and rare earthquake at 7 degrees of seismic fortification intensity, respectively. Moreover, L8 refers to PGA level of rare earthquake at 8 degrees of seismic fortification intensity. The terminology S7-US-NS means taking a group of seismic tests on the USMS model at the NS-direction with the target PGA of $88 \mathrm{~cm} / \mathrm{s}^{2}$, and, similarly, $\mathrm{S} 7-\mathrm{S}$-EW refers to taking a group of seismic tests on the SMS model at the EW-direction with the target PGA of $88 \mathrm{~cm} / \mathrm{s}^{2}$. The USMS model and SMS model were both incrementally loaded. For the USMS model, because the estimated damage pattern was much more serious under earthquakes, it was only incrementally loaded at NS-direction, with the target maximum PGA as $0.55 \mathrm{~g}$. For the SMS model, considering the estimated slight damage under earthquake, the model was loaded at two directions in turn (first at EW-direction and then at NS-direction), in order to obtain more information of seismic performance. For each PGA in tests, the three seismic waves were loaded in 


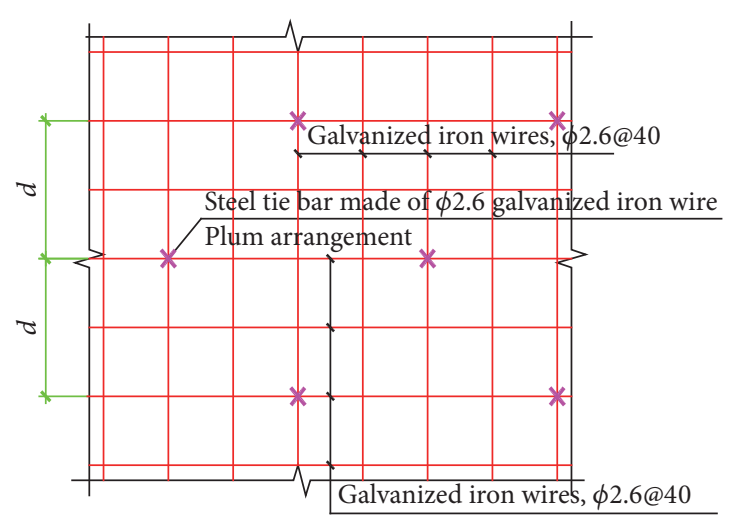

$d$ : the thickness of 3 pieces of brick

(a) Plane view of connecting nodes between concrete reinforced wall and masonry wall $(\mathrm{mm})$

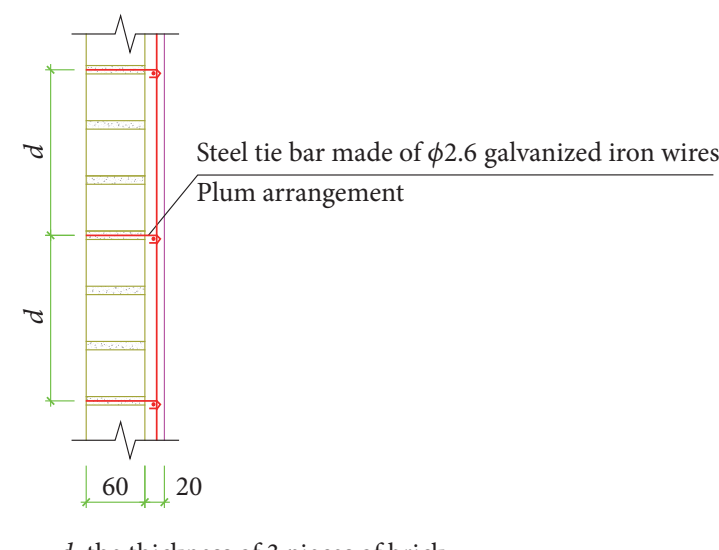

$d$ : the thickness of 3 pieces of brick

(b) Profile view of connecting nodes between concrete reinforced wall and masonry wall $(\mathrm{mm})$

FIGURE 3: Connecting nodes of the strengthened model.

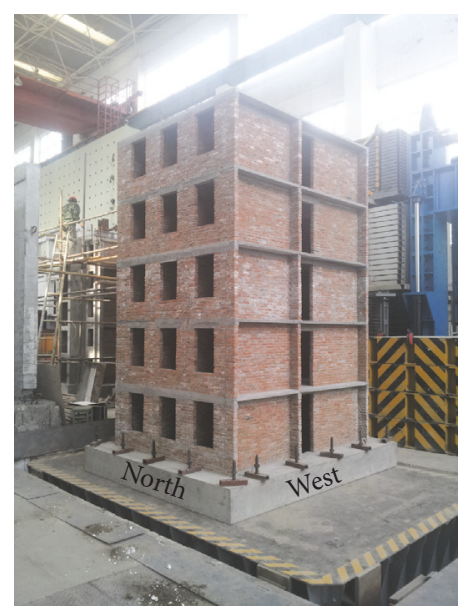

(a) 3D view of USMS model

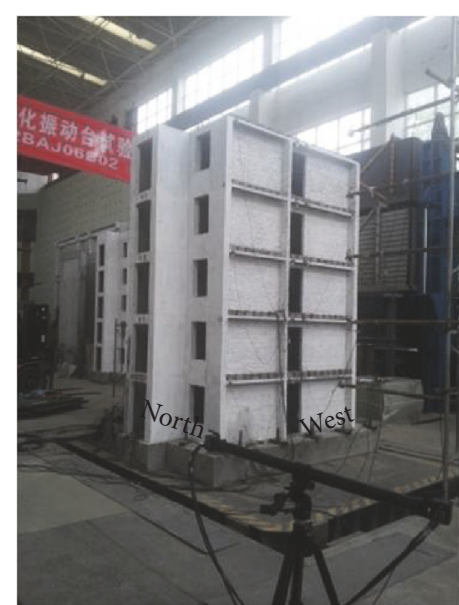

(b) 3D view of SMS model

FIGURE 4: 3D views of experimental models.

sequence with the following order: El Centro wave, Taft wave, and Shanghai wave. And they were, respectively, remarked as EL, TA, and SH in Table 2. Sweep test was considered several times to study the variation of frequencies during the tests. First, it was adopted to test the original dynamic characteristics of models before all the seismic actions. Then it was used to investigate the damage development of models after each group of target PGA. At the last stage, it was used to investigate accumulated damage of models after several earthquakes. The accelerometers located at the base allow assessing the correct acceleration of the models. The target acceleration and recorded acceleration were both presented in Table 2. It was found that the maximum difference between target and recorded acceleration was about $-22.7 \%$. The results obtained in the experimental models in the following passage will be evaluated from the real ground motions recorded.

\section{Test Results}

6.1. Variation in Fundamental Frequency. Sweep motions with frequency ranging from 1 to $40 \mathrm{~Hz}$ and with amplitude of $0.05 \mathrm{~g}$ were applied on the experimental models to determine the fundamental frequencies of the models. The models did not exhibit any visible cracking due to these low level shakes.

The dynamic characteristics for the models after each incremented input PGA were summarized in Table 3. It was observed that the strengthened model showed a much higher frequency than unstrengthened model after the same loading stage. For the USMS model, the fundamental frequency was almost constant (approximately $7.9 \mathrm{~Hz}$ ) after the test input of S7-US-NS. And it decreased to $6.52 \mathrm{~Hz}$ after the test input of M7-US-NS. Finally, it further decreased to $3.03 \mathrm{~Hz}$ after all loading tests. On the contrary, the fundamental frequency was almost constant (approximately $16 \mathrm{~Hz}$ ) for the SMS model even after the test input of M7-S-EW. Then it declined 


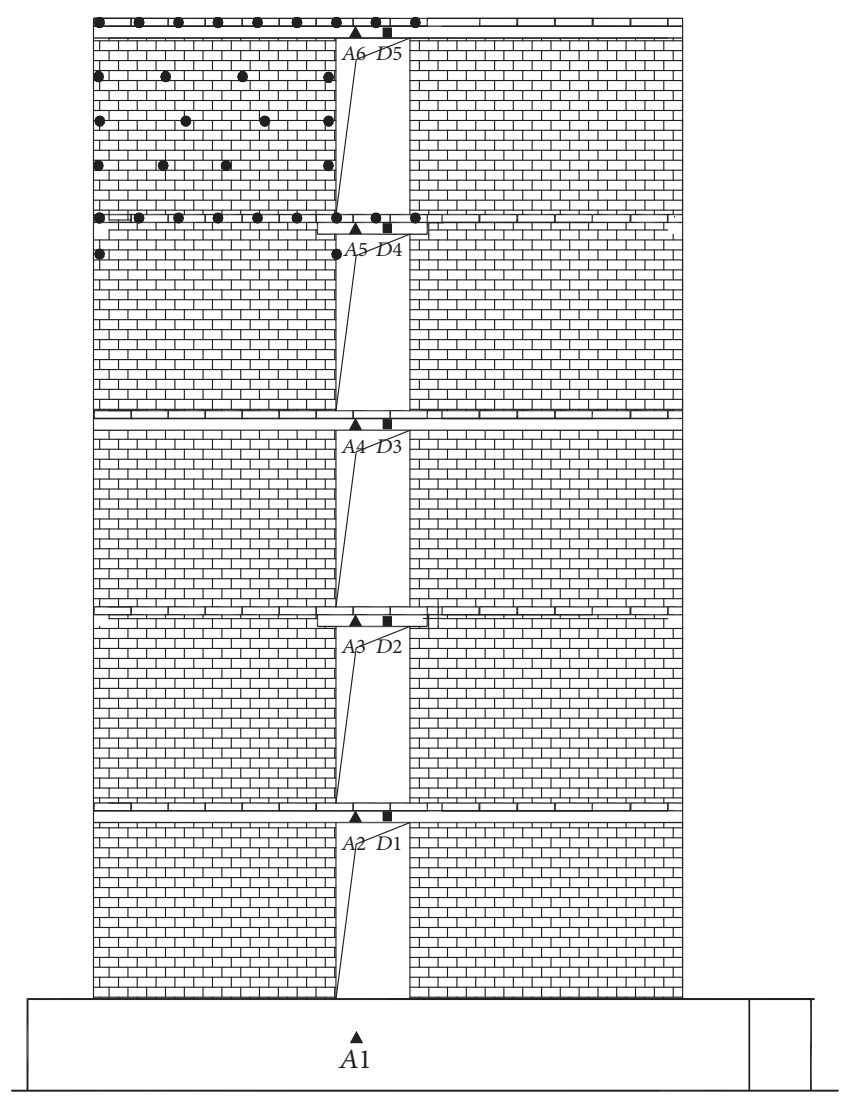

(a) The USMS model

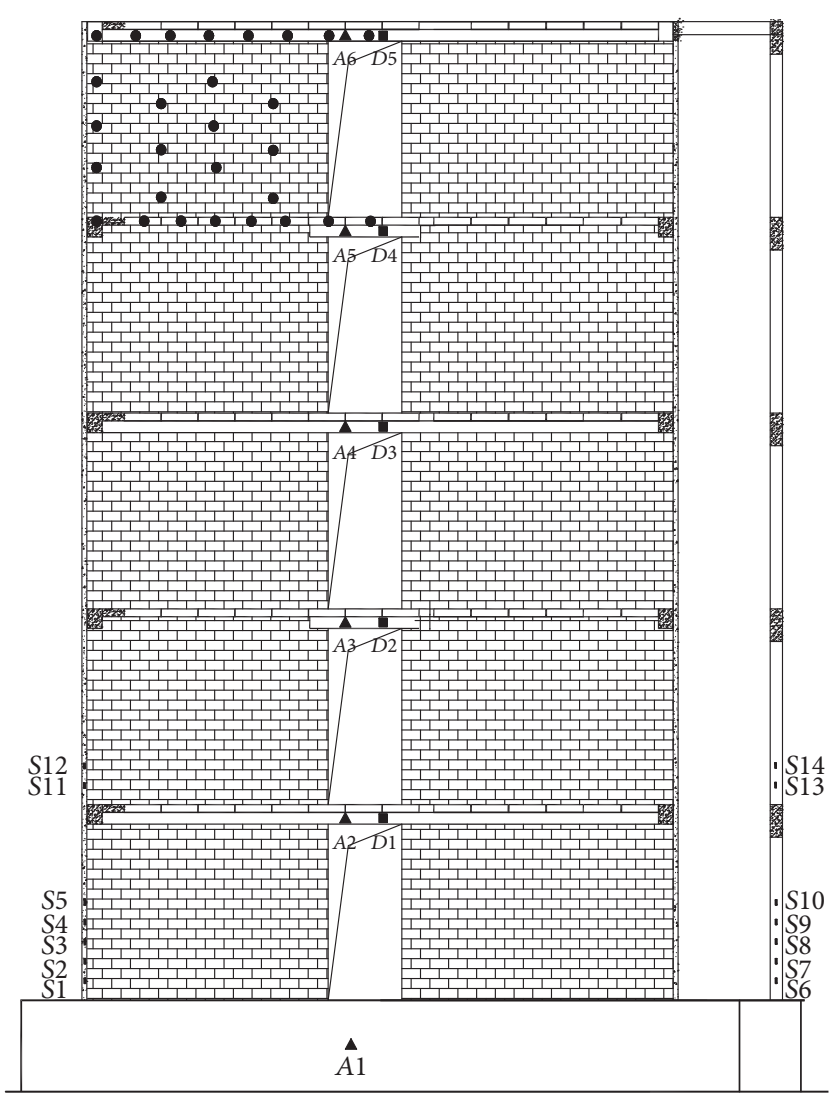

(b) The SMS model

FIGURE 5: Instrumentation arrangement of the models, in which the triangle points denote the accelerometers, the square points denote displacement meters, the circle points denote 3D dynamic target points, and the rectangle points denote strain gauges.

slightly after the test input of M7-S-NS. It should be noted that the fundamental frequency of USMS model declined much faster than SMS model after the same seismic loading. The fundamental frequency of USMS model decreased by $17.8 \%$, while that of SMS model decreased by only $6.5 \%$, under the NS-direction test with target PGA of $0.25 \mathrm{~g}$. And the USMS model basically lost the carrying capacity after the test input of L7-US-NS, accompanying a $62 \%$ reduced frequency. At the same test, the SMS model had a $19.5 \%$ reduction in frequency. At last, the SMS model had a $43.5 \%$ reduction in frequency after the test input of L8-S-NS. In the subsequent sections in this paper, only the tests loading at NS-direction were discussed to investigate the in-plane strengthening effect of structures.

6.2. Damage Pattern. The damage patterns revealed that there was a large difference between the cracking characteristics of the SMS model and USMS model. The width and length of cracks in the following passage were measured using a ruler when the dynamic input finished, wherein the crack width was the measured maximum width of the opening gap and the crack length was the measured sum length of the polylines.

For USMS model, it showed much higher crack density and much more severe damage when compared with the SMS model. Figure 7 showed the crack patterns observed in the USMS model at the last stage. Visible cracks first opened in the lower part of 3-axis wall of the first story after the test input of S7-US-NS (Taft wave). Then the opened cracks began to expand horizontally with Shanghai wave input at the same test group. A few numbers of shear diagonal stepped cracks, with about $0.1 \mathrm{~mm}$ width and about $12 \mathrm{~mm}$ length, developed at the corners of window openings in $A$-axis wall of the first story with the test input of M7-US-NS (El Centro wave). It was observed that cracks in the masonry walls increased dramatically, and nearly all masonry walls presented severe cracking after the test input of L7-US-NS (El Centro wave). At the last stage, the total number of cracks was larger than 50 , and most cracks were presented in the lower part of the model, with crack width ranging from $0.2 \mathrm{~mm}$ to $0.5 \mathrm{~mm}$. The main crack in the 1-axis wall was predominantly horizontal at the third story and presented a length of about $90 \%$ of the full wall length. The main horizontal crack in the 2 -axis wall developed from the joint of 2 -axis wall and $A$-axis wall, with a length of about $80 \%$ of the wall length. And it vertically developed near the joint of 2 -axis wall and $B$-axis wall. In the 3 -axis wall, the two major opened cracks were, respectively, horizontally developed at mid height and upper height of the fourth story, nearly dividing the wall into discrete horizontal blocks. It should be noted that most cracks horizontally 

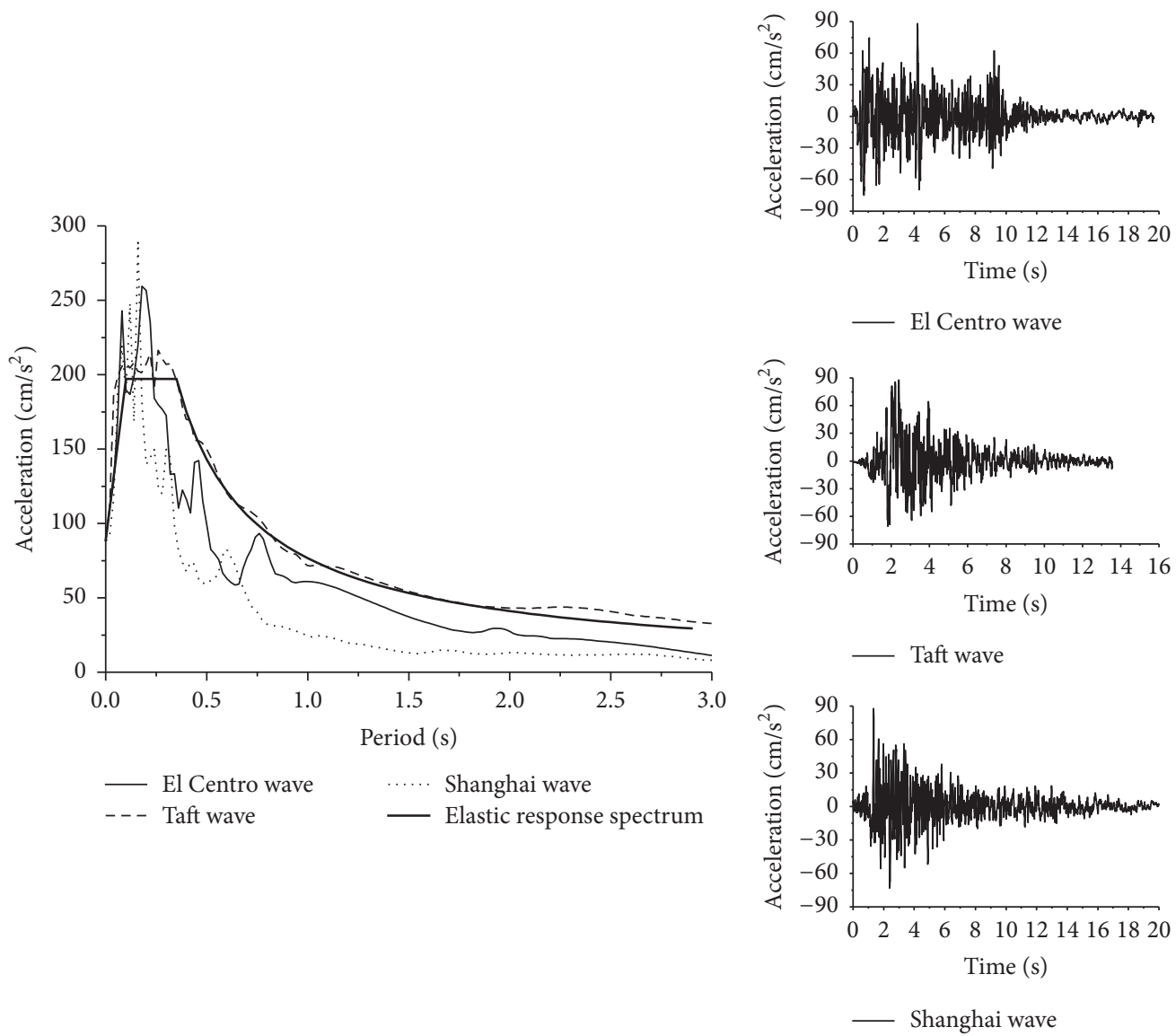

FIGURE 6: The proposed elastic response spectrum and the response spectrums obtained from the compressed accelerograms.

TABLE 2: Test sequences for experimental models.

\begin{tabular}{lccccccc}
\hline & \multicolumn{3}{c}{ The USMS model } & & \multicolumn{3}{c}{ The SMS model } \\
Test & Wave & Target PGA (gal) & Recorded PGA (gal) & Test & Wave & Target PGA (gal) & Recorded PGA (gal) \\
\hline S7-US-NS & EL, TA, SH & $88,88,88$ & $84,81,74$ & S7-S-EW & EL, TA, SH & $88,88,88$ & $126,68,110$ \\
M7-US-NS & EL, TA, SH & $250,250,250$ & $212,196,213$ & M7-S-EW & EL, TA, SH & $250,250,250$ & $286,194,266$ \\
L7-US-NS & EL, TA, SH & $550,550,550$ & $442,431,434$ & S7-S-NS & EL, TA, SH & $88,88,88$ & $88,68,91$ \\
& & & & M7-S-NS & EL, TA, SH & $250,250,250$ & $225,211,280$ \\
& & & & L7-S-NS & EL, TA, SH & $550,550,550$ & $462,549,552$ \\
& & & & L8-S-NS & EL, TA, SH & $1000,1000,1000$ & $865,777,1141$ \\
\hline
\end{tabular}

TABLE 3: Fundamental frequencies of USMS model and SMS model (Hz).

\begin{tabular}{llccccc}
\hline Test model & & Sweep 1 & Sweep 2 & Sweep 3 & Sweep 4 & Sweep 5 \\
\hline Model A & NS-direction & 7.94 & 7.89 & 6.52 & 3.03 & - \\
Model B & EW-direction & 16.06 & 15.96 & - & - & - \\
& NS-direction & 11.86 & 11.78 & 11.09 & 9.55 \\
\hline
\end{tabular}

developed in the walls normal to the loading direction. And they were mainly along the block-mortar interface, appearing to be the result of out-plane flexural resisting mechanism. But it was observed that the cracking pattern in the walls normal to the loading direction was significantly different from the one in the walls parallel to the loading direction. Stepped cracks appeared at the corners of window openings in the
$A$-axis wall from the first story to the fifth story. In the $B$ axis wall, it was characterized by X-shape cracks developed between the door openings at the second story. At the last stage, several clay blocks slide out of the wall from the right corner of the door opening between 1/1-axis wall and 2-axis wall. Stepped diagonal smear cracks appeared at the corners of window openings in the $C$-axis wall from the first story to 


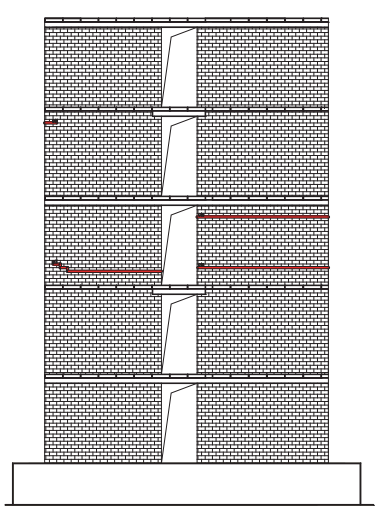

(a) The 1-axis wall

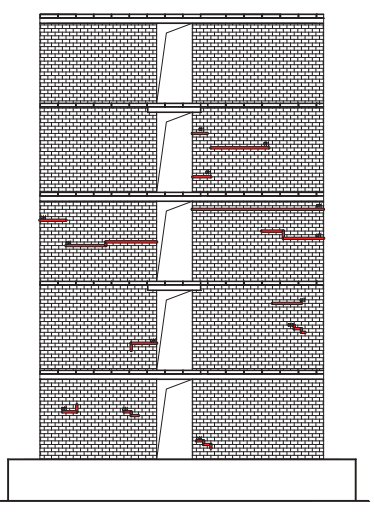

(b) The 3-axis wall

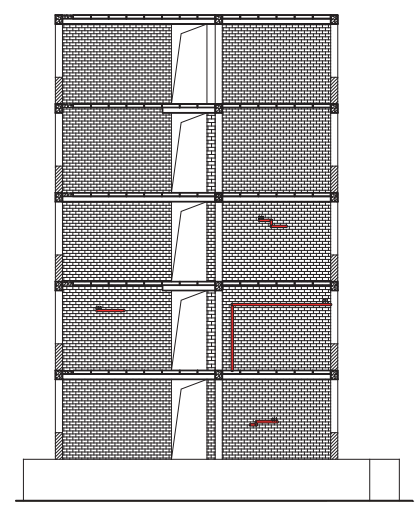

(c) The 1/1-axis wall

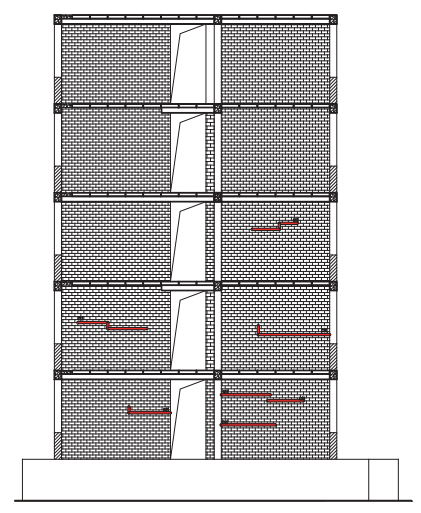

(d) The 2/1-axis wall

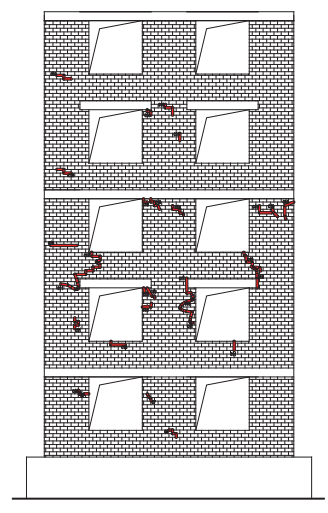

(e) The $A$-axis wall

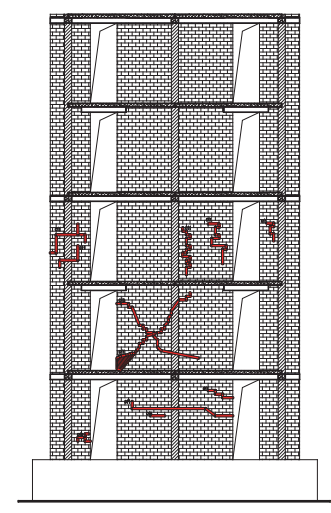

(f) The $B$-axis wall

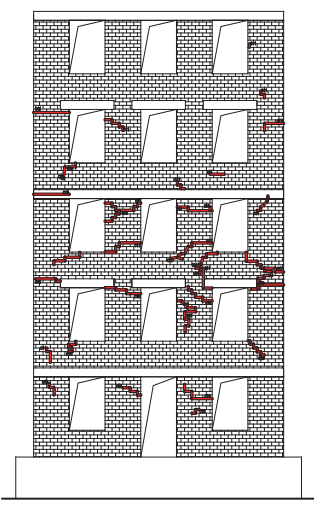

(g) The $C$-axis wall

FIGURE 7: The crack pattern of USMS model at the last stage (target PGA $=0.55 \mathrm{~g}$ ).

the fifth story. Corresponding to the symmetrical feature of the model, the damage pattern presented in $C$-axis wall was similar to the one in $A$-axis wall. In conclusion, the forming of cracks during the tests was significant, and the cracks density was clearly higher in the walls with openings. It should be stressed that the USMS model showed no collapse, in spite of the very severe damage, but the displacement meters were disassembled after the L7-US-NS (El Centro wave) test to protect the equipment.

On the contrary, almost no cracking was observed in the SMS model at this stage. Moreover, there was no obvious crack developed even under the test input of M7-S-EW, except the peeling off of lime slurries on the model.

At last, compared with the SMS model, the damage pattern of USMS model was followed: (1) clear diagonal cracks located mainly at the corners of openings; (2) the damage was spread all over the model; (3) the cracking occurred at early loading stage; (4) it was heavily damaged and beyond repair when the loading was complete.

6.3. Evaluation of the Displacements and Lateral Drifts. The displacements measured by displacement meters were verified by 3D dynamic displacement acquisition system. The displacement histories measured by the two systems were shown in Figure 8, and they showed well-matched results.
The absolute displacement profiles were recorded from displacement meters, and the lateral drifts were calculated from the absolute displacements. Unfortunately there was no displacement meter placed on the concrete base, resulting in the missing drift for the first layer. Also it should be mentioned that displacement profile for USMS model at the test input of S7-US-NS was missed due to the unbooted acquisition device, and the displacement profiles recorded at the test input of L7-US-NS (Taft wave and Shanghai wave) were also missed due to the disassembled displacement meters considering the severe damage and high probability of collapse of the unstrengthened model.

Figure 9 showed the envelopes of maximum displacements for the strengthened and unstrengthened models, respectively. The displacements presented were the maximum absolute values obtained for each test input. The USMS model exhibited a profile with small differences along the height of the model when the target input PGA was less than or equal to $0.25 \mathrm{~g}$. Incidentally, it presented a different profile close to collapse after the target input PGA of $0.55 \mathrm{~g}$, due to the severe damage distributed in the model. On the contrary, there were small differences between displacements along the height of the SMS model, meaning that the seismic action of the model was similar to a rigid block. Up to this stage, the displacement profiles were almost linear in elevation, as a result of the low level of damage. For the USMS model, the higher drifts were 


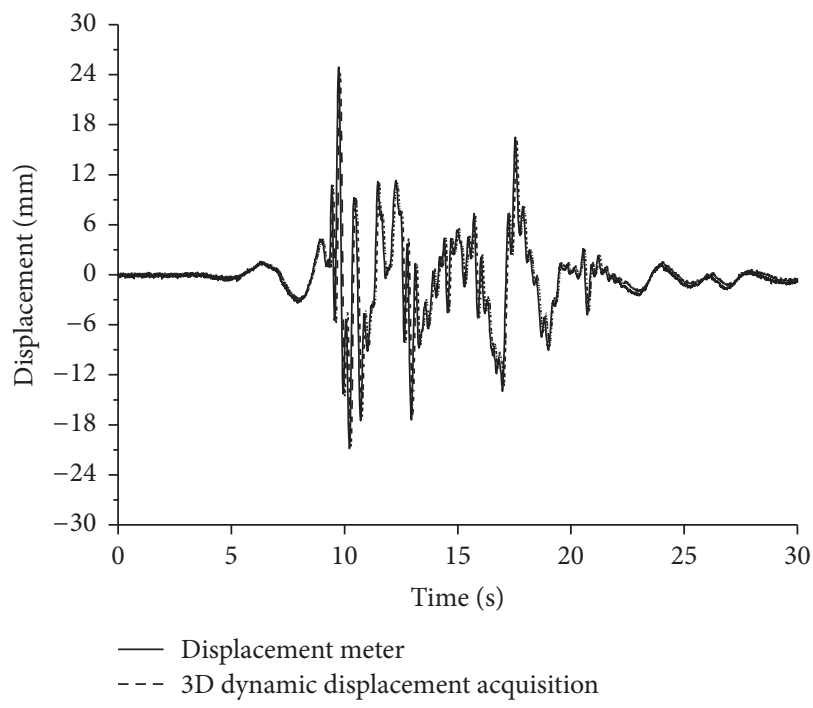

(a) Displacement histories of USMS model under test input of L7-US-NS (El Centro wave)

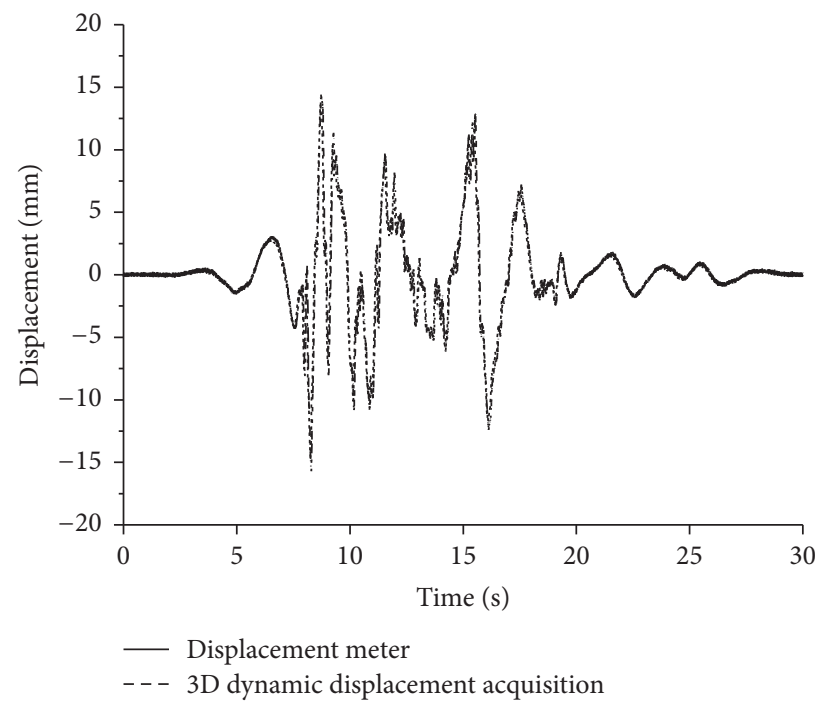

(b) Displacement histories of SMS model under test input of L7-S-NS (El Centro wave)

FIGURE 8: The displacement histories measured by the displacement meters and 3D dynamic displacement acquisition system.

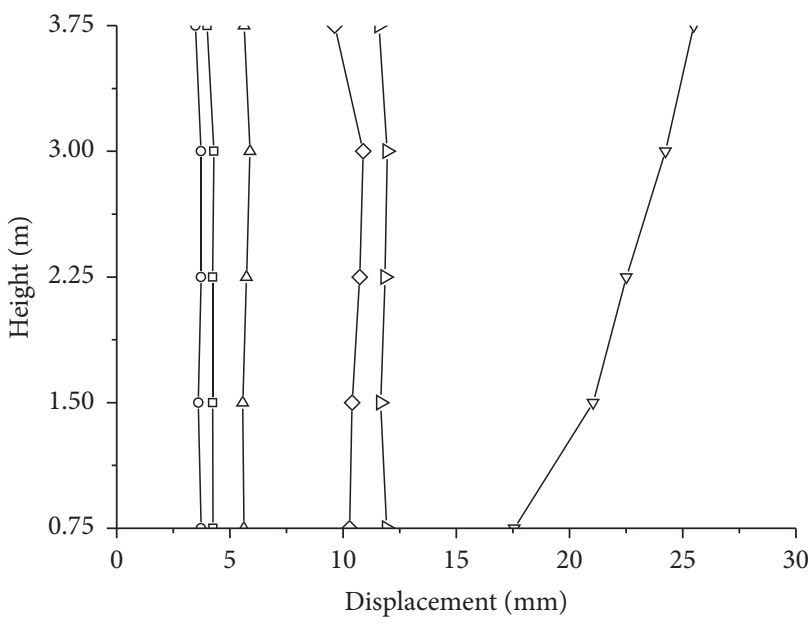

$\begin{array}{ll}-\nabla-\text { L7-US-NS (El Centro) } & -\Delta-\text { M7-US-NS (El Centro) } \\ -\diamond-\text { M7-US-NS (Shanghai) } & -\circ-\text { S7-US-NS (Shanghai) } \\ -\triangleright-\text { M7-US-NS (Taft) } & - \text { - S S7-US-NS (Taft) }\end{array}$

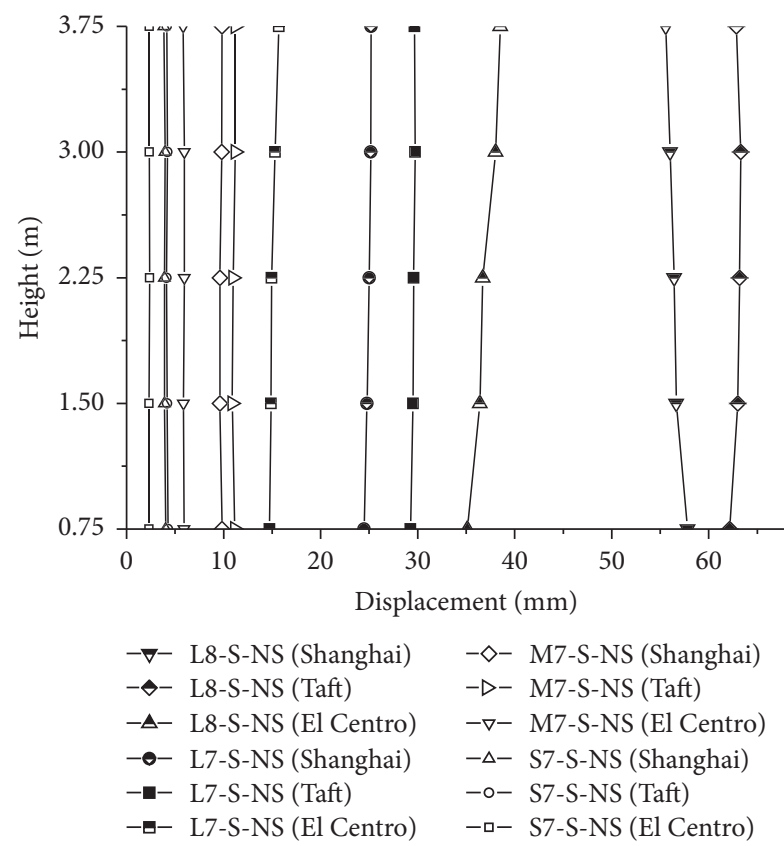

(b) The SMS model

(a) The USMS model

FIGURE 9: Envelopes of maximum displacements of USMS model and SMS model.

usually found at the second floor level. It was considered associating with the severe damage developed at the second story and the third story. When the first crack appeared in the second story, the target input PGA was $0.088 \mathrm{~g}$ and the maximum interstory drift was $0.02 \%$. The lateral drifts found for the target input PGA of $0.55 \mathrm{~g}$ were of $0.46 \%$ in the second floor and of $0.19 \%$ in the third floor, corresponding to the X-shape cracking in the second story and distributed smear cracks in the second story and the third story. When compared with USMS model, the interstory drifts of the
SMS model were quite low. The higher interstory drifts were usually found at the second floor level and with a maximum value of $0.17 \%$ for the target input PGA of $1.0 \mathrm{~g}$, with no visible crack. In conclusion, the SMS model showed more excellent deformation capacity when compared with the USMS model.

6.4. Amplification Factors for Acceleration. The amplification factors were obtained from the ratio between the peak acceleration recorded at the floor levels and at the concrete base. 


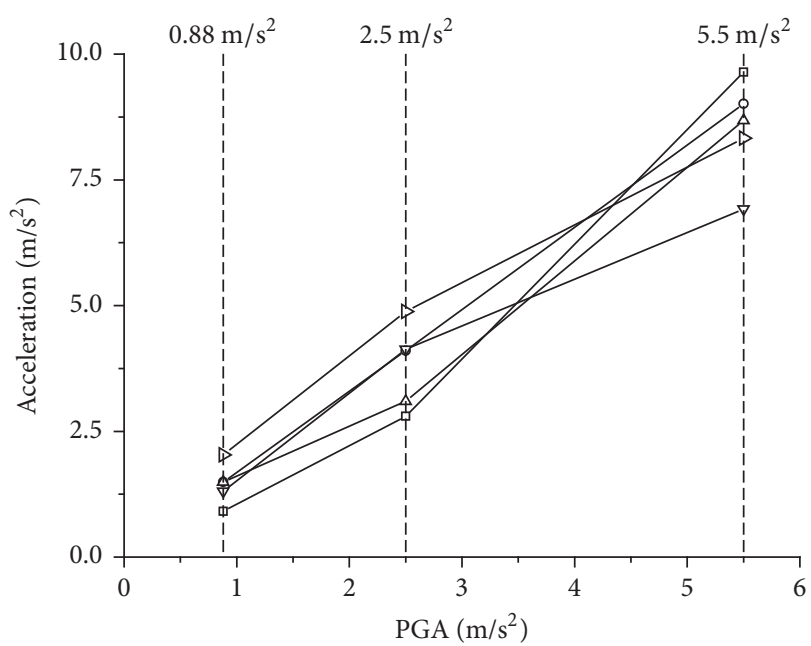

$\begin{array}{ll}-\square-\text { First story, El Centro } & -\nabla-\text { Forth story, El Centro } \\ -\circ-\text { Second story, El Centro } & \rightarrow-- \text { Fifth story, El Centro } \\ -\Delta-\text { Third story, El Centro } & \end{array}$

(a) El Centro wave

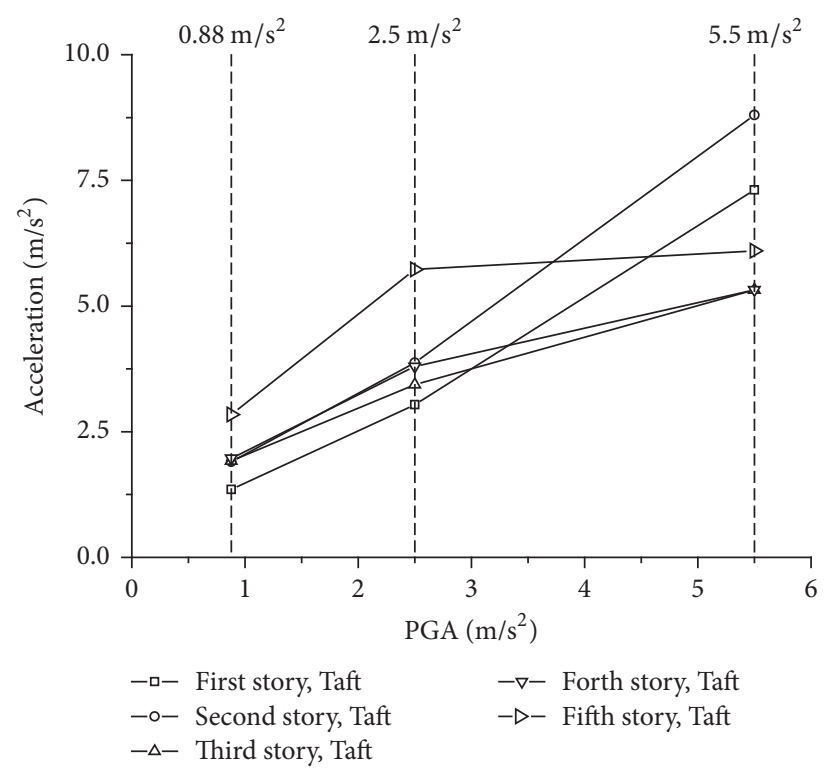

(b) Taft wave

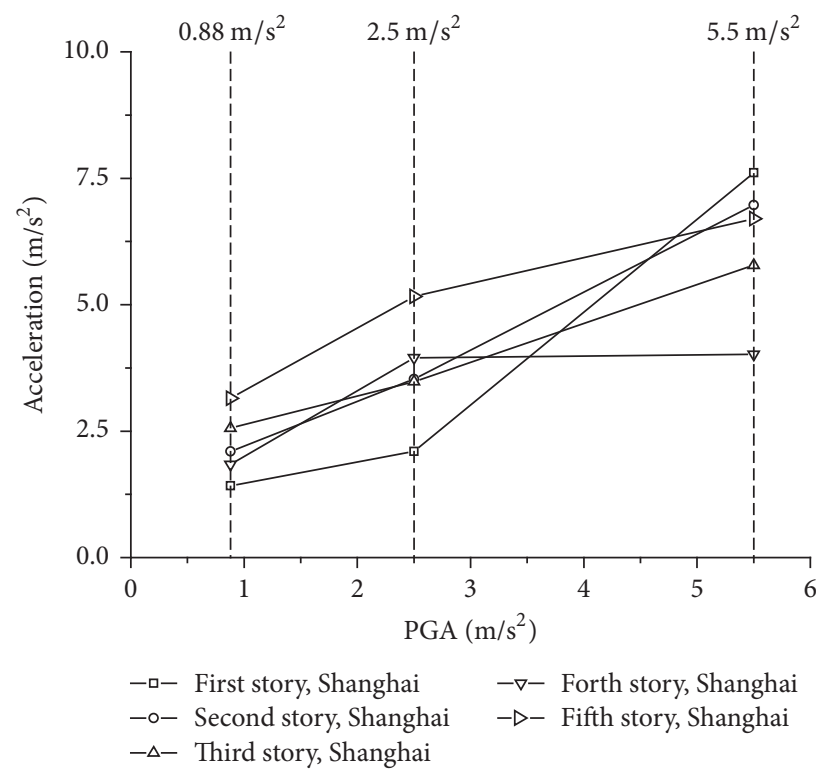

(c) Shanghai wave

FIGURE 10: Story acceleration versus target PGA of USMS model.

The acceleration for different test inputs was shown in Figures 10 and 11 for the USMS model and SMS model, respectively. It was observed that the acceleration at floor levels increased with the incremented input PGA for the two models. The only exception occurred on the heavily damaged USMS model under the test input of L7-US-NS, which was due to the predominant shear sliding mechanism developed at the unitmortar interfaces. For the USMS model, the acceleration increased along the height of the model at early loading stage, with the largest value appearing at the fifth floor. While the acceleration showed different results under the test input of L7-US-NS. At this loading stage, larger acceleration appeared at the first and the second floor, and the least acceleration appeared at the fourth story. It was corresponding to the severe damage at the lower part of the model. Compared with the SMS model, higher amplifications were recorded in the USMS model at the early loading stage, mainly due to the lower fundamental frequency. Simultaneously, in the SMS model, acceleration at higher inputs level was also different from the results obtained at lower inputs level. At early loading stage, the acceleration of SMS model showed largest acceleration at the fifth story and showed similar acceleration between the other four stories, while at the last loading stage, the larger acceleration presented at the first and the second floors, corresponding to the slight damage. 


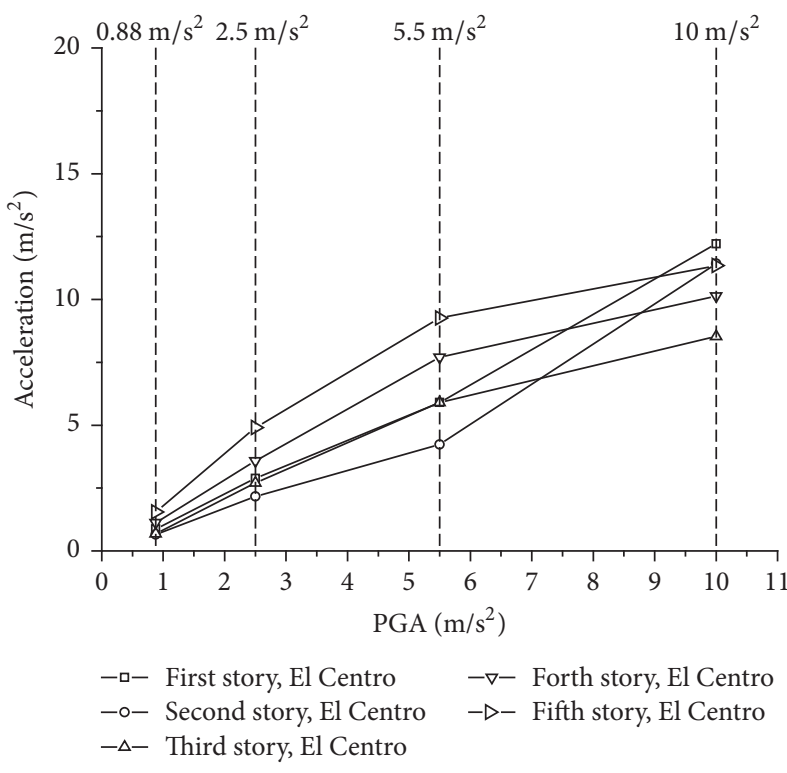

(a) El Centro wave

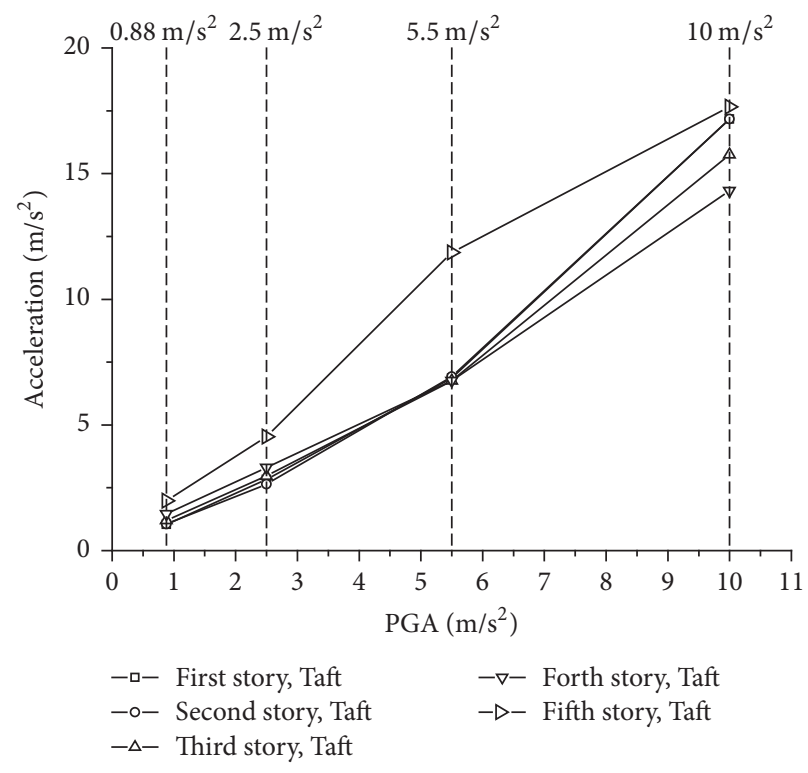

(b) Taft wave

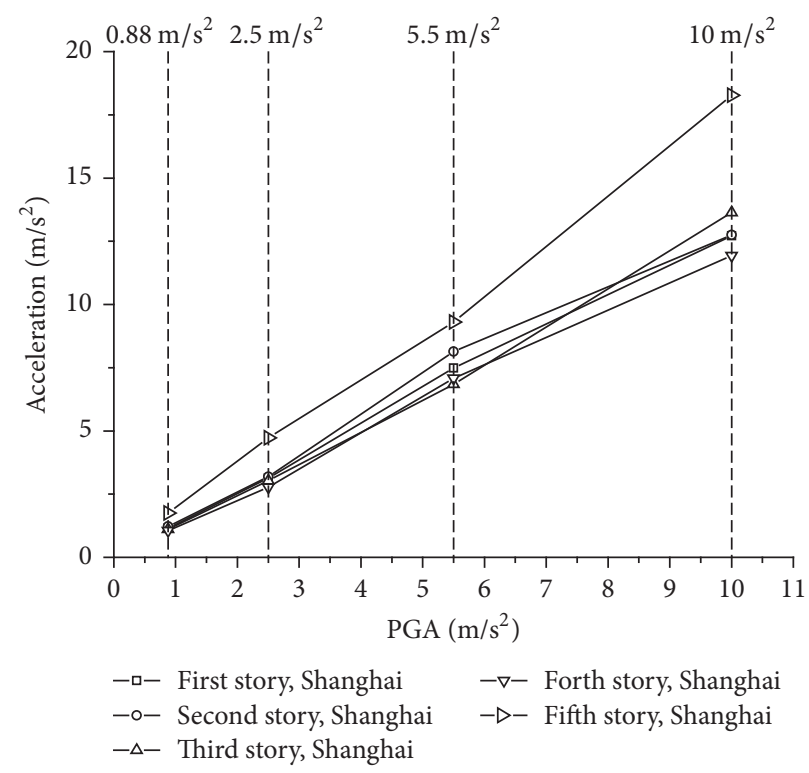

(c) Shanghai wave

FIGURE 11: Story acceleration versus target PGA of SMS model.

In the SMS model, the amplification factor reduction of the fourth story, between the test input of S7-S-NS and the L7-S-NS, was with a degradation of $20 \%$. And the largest amplification factor reduction was with a degradation of $28 \%$, between the first seismic loading and the last seismic loading, while in the USMS model, the largest amplification reduction at the last loading stage was presented at the third story, with a reduction of more than $64 \%$, from 2.24 to 0.73 . The USMS model represented much more severe damage than the SMS model even when they were applied by the same seismic loading.

6.5. Concrete Strain. The maximum amplitudes of the recorded strain at the points S1 and S14 in SMS model, under test inputs of S7-S-NS and M7-S-NS, were shown in Table 4. The strain $\varepsilon_{t}$ corresponding to the tensile strength $f_{t}$ was approximately equal to $57 \times 10^{-6}\left(\varepsilon_{t}=f_{t} / E_{c}\right)$. It was observed that the maximum amplitudes of the recorded strain were less than $57 \times 10^{-6}$ when the input PGA was less than or equal to $0.25 \mathrm{~g}$. The results were matched well with the trend observed in displacements and acceleration.

\section{Concluding Remarks}

The present work aimed at assessing the experimental seismic behaviour of masonry buildings through shaking table tests. Two reduced 1:4 scaled models were built. One of them 
TABLE 4: The maximum strain of concrete at the points S1 and S14 $(\mu \varepsilon)$.

\begin{tabular}{|c|c|c|c|c|c|c|}
\hline \multirow{3}{*}{ Test condition } & \multicolumn{6}{|c|}{ Seismic loading } \\
\hline & \multicolumn{2}{|c|}{ El Centro wave } & \multicolumn{2}{|c|}{ Taft wave } & \multicolumn{2}{|c|}{ Shanghai wave } \\
\hline & S1 & S14 & S1 & S14 & S1 & S14 \\
\hline S7-S-NS & 8.3 & 64.8 & 12.3 & 17.4 & 16.7 & 26.1 \\
\hline M7-S-NS & 24.8 & 41.9 & 32.1 & 53.7 & 31.2 & 54.9 \\
\hline
\end{tabular}

was strengthened masonry structure and the other one was unstrengthened masonry structure. The models were subjected to incremental seismic input loading. The following conclusions can be pointed out:

(1) The strengthened and unstrengthened models exhibited very distinct different behaviours concerning the crack patterns and deformation profiles.

(2) The strengthening technology of installing prefabricated concrete walls clearly improved the seismic performance of masonry structure, leading to adequate structural robustness and high ability of deformation at high seismic loading.

(3) No visible cracking presented in the strengthened model after the test sequence, while measured data, such as frequencies, acceleration, and strains, illustrated the tiny damage after the input PGA of $0.55 \mathrm{~g}$, indicating the necessary and accuracy of measurement techniques.

(4) Diagonal stepped cracks developed all over the unstrengthened structure in the masonry walls parallel to the loading direction, while cracks developed horizontal with large length in the walls normal to the loading direction. Almost all cracks developed at the concrete block-mortar interfaces, except a few shear damage of block unites.

(5) In spite of the extreme damage developed and large lateral drifts showed, the unstrengthened model was not collapsed, indicating the well seismic performance at moderate seismicity region.

\section{Conflicts of Interest}

The authors declare that they have no conflicts of interest.

\section{Acknowledgments}

This work was supported by the National Natural Science Foundation of China (Grant nos. 51678302 and 51678301), the Major Program of Natural Science Foundation of the Jiangsu Higher Education Institutions of China (14KJA560001), and the General University Postgraduate Research and Creative Project of Jiangsu Province (Grant no. CXZZ13_0440).

\section{References}

[1] G. Ramaglia, G. P. Lignola, and A. Prota, "Collapse analysis of slender masonry barrel vaults," Engineering Structures, vol. 117, pp. 86-100, 2016.
[2] C. Akcay, T. S. Bozkurt, B. Sayin, and B. Yildizlar, "Seismic retrofitting of the historical masonry structures using numerical approach," Construction and Building Materials, vol. 113, pp. 752-763, 2016.

[3] F. Graziotti, U. Tomassetti, A. Penna, and G. Magenes, "Out-ofplane shaking table tests on URM single leaf and cavity walls," Engineering Structures, vol. 125, pp. 455-470, 2016.

[4] V. Giamundo, V. Sarhosis, G. P. Lignola, Y. Sheng, and G. Manfredi, "Evaluation of different computational modelling strategies for the analysis of low strength masonry structures," Engineering Structures, vol. 73, pp. 160-169, 2014.

[5] N. Kabashi, C. Krasniqi, Q. Kadiri et al., "Masonry Structures Confinement with Glass Fiber Reinforcement Polymers," in Proceedings of the 13th International Conference "Standardization, Protypes and Quality: A Means of Balkan Countries' Collaboration, November 2016, Brasov, Romania.

[6] F. Ersubasi and H. H. Korkmaz, "Shaking table tests on strengthening of masonry structures against earthquake hazard," Natural Hazards and Earth System Science, vol. 10, no. 6, pp. 12091220, 2010.

[7] T. Nakagawa, T. Narafu, H. Imai, T. Hanazato, Q. Ali, and C. Minowa, "Collapse behavior of a brick masonry house using a shaking table and numerical simulation based on the extended distinct element method," Bulletin of Earthquake Engineering, vol. 10, no. 1, pp. 269-283, 2012.

[8] H. Smoljanović, Ž. Nikolić, and N. Živaljić, "A combined finitediscrete numerical model for analysis of masonry structures," Engineering Fracture Mechanics, vol. 136, pp. 1-14, 2015.

[9] L. Facchini and M. Betti, "Simplified seismic analysis of disordered masonry towers," ASCE-ASME Journal of Risk and Uncertainty in Engineering Systems, Part A: Civil Engineering, vol. 2, no. 2, 2016.

[10] L. A. S. Kouris, A. Penna, and G. Magenes, "Seismic damage diagnosis of a masonry building using short-term damping measurements," Journal of Sound and Vibration, vol. 394, pp. 366-391, 2017.

[11] E. Vintzileou, C. Mouzakis, C.-E. Adami, and L. Karapitta, "Seismic behavior of three-leaf stone masonry buildings before and after interventions: shaking table tests on a two-storey masonry model," Bulletin of Earthquake Engineering, vol. 13, no. 10, pp. 3107-3133, 2015.

[12] M. Tomaževič and M. Gams, "Shaking table study and modelling of seismic behaviour of confined AAC masonry buildings," Bulletin of Earthquake Engineering, vol. 10, no. 3, pp. 863893, 2012.

[13] R. Bairrão and M. J. Falcão Silva, "Shaking table tests of two different reinforcement techniques using polymeric grids on an asymmetric limestone full-scaled structure," Engineering Structures, vol. 31, no. 6, pp. 1321-1330, 2009.

[14] Y.-H. Tu, T.-H. Chuang, P.-M. Liu, and Y.-S. Yang, "Out-ofplane shaking table tests on unreinforced masonry panels in RC frames," Engineering Structures, vol. 32, no. 12, pp. 3925-3935, 2010. 
[15] T. Hanazato, Y. Tominaga, T. Mikoshiba et al., "Shaking table test of full scale model of timber framed brick masonry walls for structural restoration of tomioka silk mill, registered as a tentative world cultural heritage in Japan," in Historical Earthquake-Resistant Timber Frames in the Mediterranean Area, pp. 83-93, Springer International Publishing, 2015.

[16] K. Beyer, M. Tondelli, S. Petry, and S. Peloso, "Dynamic testing of a four-storey building with reinforced concrete and unreinforced masonry walls: prediction, test results and data set," Bulletin of Earthquake Engineering, vol. 13, no. 10, pp. 30153064, 2015.

[17] V. Giamundo, G. P. Lignola, G. Maddaloni, A. Balsamo, A. Prota, and G. Manfredi, "Experimental investigation of the seismic performances of IMG reinforcement on curved masonry elements," Composites Part B: Engineering, vol. 70, pp. 53-63, 2015.

[18] P. B. Lourenço, L. Avila, G. Vasconcelos, J. P. P. Alves, N. Mendes, and A. C. Costa, "Experimental investigation on the seismic performance of masonry buildings using shaking table testing," Bulletin of Earthquake Engineering, vol. 11, no. 4, pp. 1157-1190, 2013.

[19] R. Ma, L. Jiang, M. He, C. Fang, and F. Liang, "Experimental investigations on masonry structures using external prestressing techniques for improving seismic performance," Engineering Structures, vol. 42, pp. 297-307, 2012.

[20] D. V. Oliveira, I. Basilio, and P. B. Loureņo, "Experimental behavior of FRP strengthened masonry arches," Journal of Composites for Construction, vol. 14, no. 3, pp. 312-322, 2010.

[21] N. Ismail and J. M. Ingham, "In-plane and out-of-plane testing of unreinforced masonry walls strengthened using polymer textile reinforced mortar," Engineering Structures, vol. 118, pp. 167-177, 2016.

[22] N. Sathiparan, K. Sakurai, M. Numada, and K. Meguro, "Seismic evaluation of earthquake resistance and retrofitting measures for two story masonry houses," Bulletin of Earthquake Engineering, vol. 12, no. 4, pp. 1805-1826, 2014.

[23] M. Tomaževič, I. Klemenc, and P. Weiss, "Seismic upgrading of old masonry buildings by seismic isolation and CFRP laminates: a shaking-table study of reduced scale models," Bulletin of Earthquake Engineering, vol. 7, no. 1, pp. 293-321, 2009.

[24] A. Preciado, S. T. Sperbeck, and A. Ramírez-Gaytán, "Seismic vulnerability enhancement of medieval and masonry bell towers externally prestressed with unbonded smart tendons," Engineering Structures, vol. 122, pp. 50-61, 2016. 


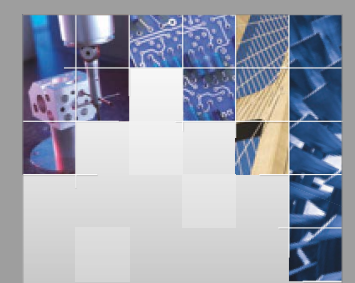

\section{Enfincering}
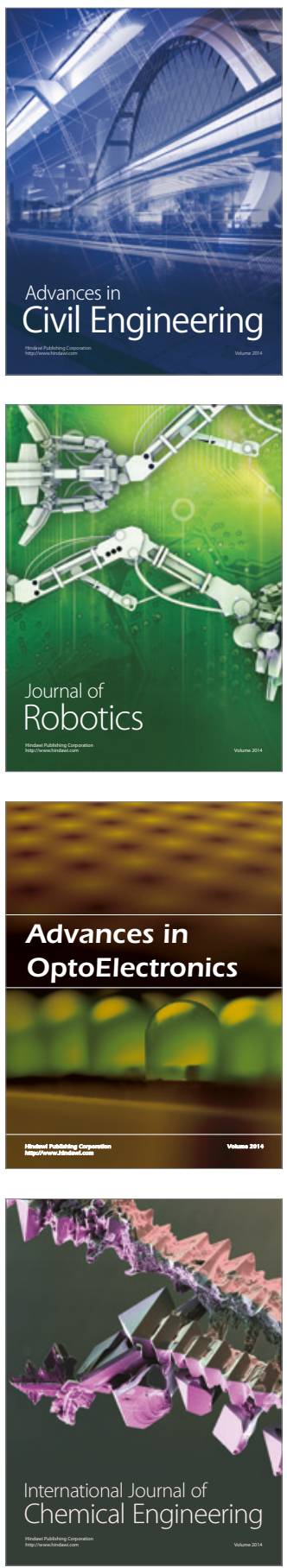

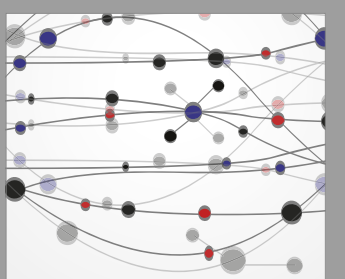

The Scientific World Journal

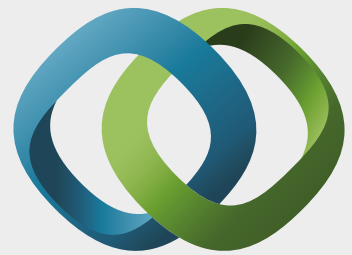

\section{Hindawi}

Submit your manuscripts at

https://www.hindawi.com
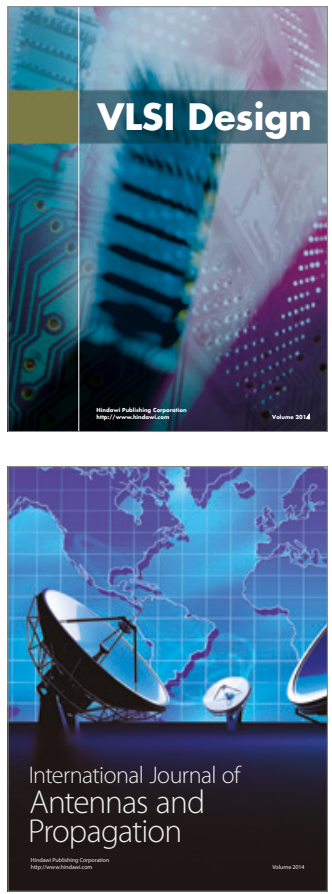

\section{Rotating}

Machinery
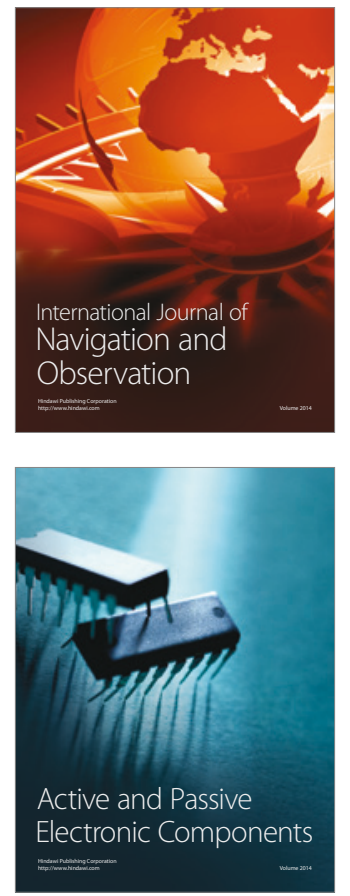
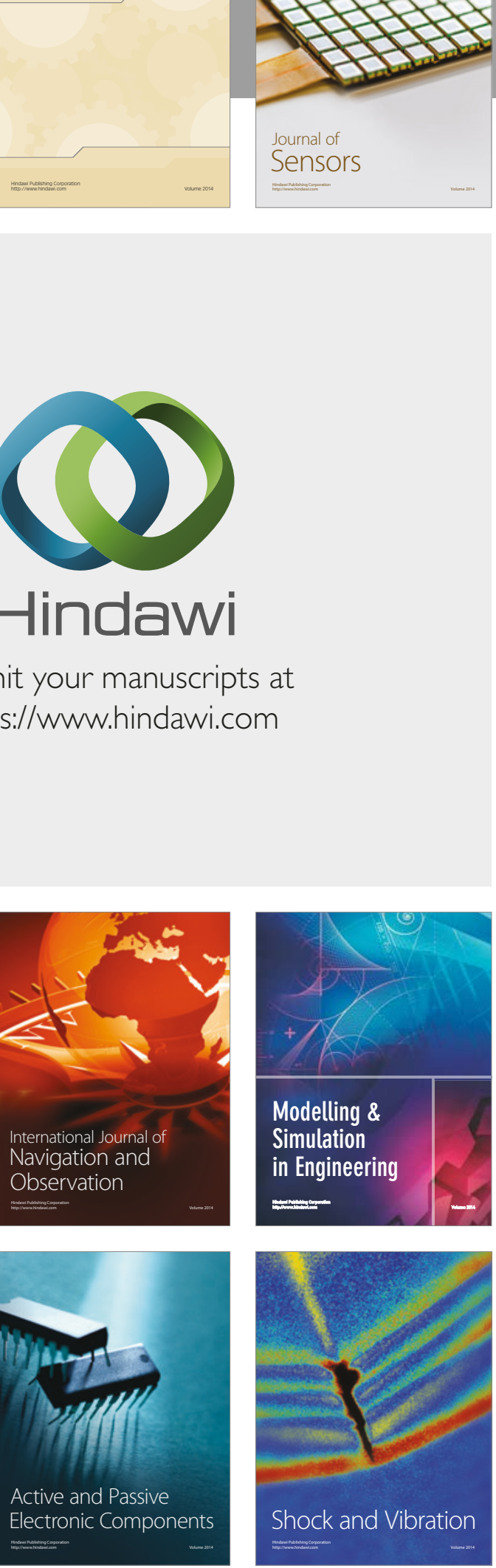
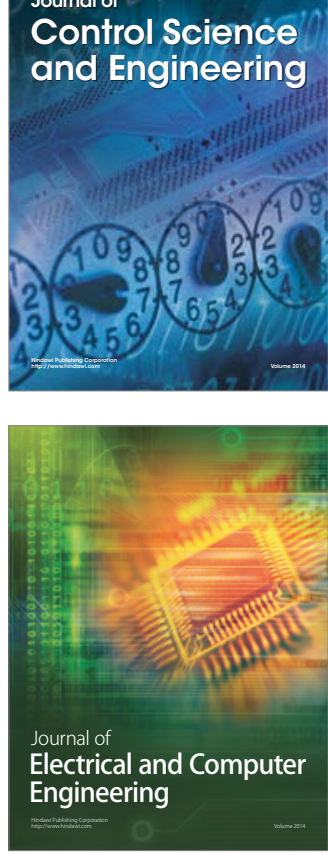

Distributed

Journal of

Control Science

and Engineering
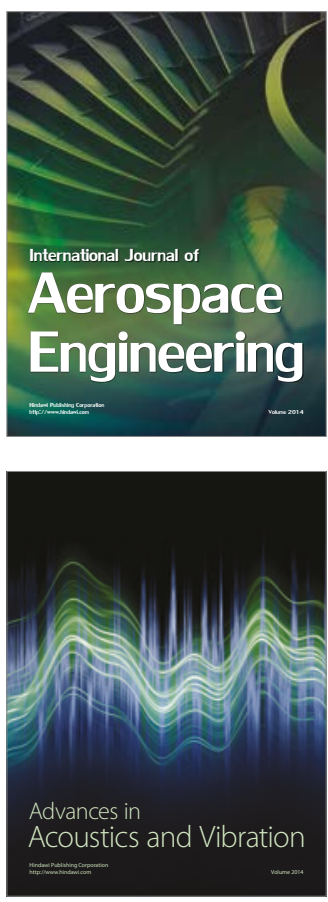

Sensor Networks 